\title{
Arte-ciencia en micorriza: una experiencia de aprendizaje integrado entre Biología y Artes Visuales en pandemia
}

\author{
Art-Science in Mycorrhiza: An Integrative Learning Experience Between \\ Biology and Visual Arts in Pandemic \\ César Piñones-Cañete ${ }^{1}$; Cileni Pastén-Tricallotis ${ }^{2}$; César Jopia-Quiñones ${ }^{3}$
}

\begin{abstract}
RESUMEN
En este artículo se presentan los resultados de una experiencia pedagógica desarrollada con doce estudiantes de primaria y secundaria de la ciudad de Salamanca, Chile, la cual tuvo como objetivo construir montajes artísticos que dieran cuenta de la diversidad del reino fungi y evidenciaran analogías basadas en la relación simbiótica de la micorriza. La experiencia se desarrolló bajo el contexto sanitario derivado de la pandemia de COVID-19 y contempló la ejecución de una secuencia didáctica de cinco etapas. El trabajo con los/as estudiantes se realizó en reuniones en línea y a través de un aula móvil que se trasladó a sus hogares. Se logró terminar ocho montajes y tres quedaron a la espera de ser finalizados tras el retorno a clases presenciales. Las obras y el análisis de las mismas por parte de los/as estudiantes se resumieron en un video testimonial sobre la experiencia. Dicho documental fue seleccionado como obra destacada en un encuentro escolar nacional. La experiencia logró reconectar a un grupo de adolescentes con el placer de aprender en comunidad, pese al aislamiento. Por ello, el presente trabajo postula que las temáticas en la interface ciencia-arte son un recurso fructífero para mitigar los efectos emocionales de la pandemia.
\end{abstract}

Palabras claves: land art; reino fungi; micorriza; método de proyectos; aprendizaje integrado; educación en pandemia; COVID-19.

\footnotetext{
1 Profesor de Biología y Ciencias Naturales, Colegio Sagrado Corazón, Copiapó, Chile; magíster en Educación Ambiental, Universidad de Playa Ancha, Valparaíso, Chile; c.pinones@liceosagradocorazon.cl; https://orcid.org/0000-0002-7204-3355.

2 Docente, Colegio Cumbres del Choapa, Salamanca, Chile; licenciada en Educación y pedagoga en Artes Visuales, Universidad de Chile; pastentricallotis@gmail.com.

${ }^{3}$ Director de Revista Bioma, Santiago, Chile; fotógrafo y realizador audiovisual.
} 


\section{ABSTRACT}

This article presents the results of a pedagogical experience developed with twelve elementary and high school students from the city of Salamanca, Chile, which aimed to construct artistic montages that would account for the diversity of the fungi kingdom and show analogies based on the symbiotic relationship of mycorrhiza. The experience was developed under the health context derived from the COVID-19 pandemic and included the execution of a five-stage didactic sequence. The work with the students was carried out in online meetings and through a mobile classroom that was moved to their homes. Eight assemblies were completed and other three are awaiting completion after returning to face-to-face classes. The works and their analysis by the students were summarized in a testimonial video about the experience. This documentary was selected as an outstanding work in a national school meeting. The experience managed to reconnect a group of adolescents with the pleasure of learning in community, despite the isolation. Therefore, the present work postulates that the themes in the science-art interface are a fruitful resource to mitigate the emotional effects of the pandemic.

Keywords: Land art; fungi kingdom; mycorrhiza; project method; integrated learning; education in pandemic; COVID-19.

La micorriza como asociación simbiótica entre un árbol y un hongo no solo constituye una rica relación ecológica interespecífica a explorar desde la biología, sino que también puede ser gatilladora de inspiración artística en el contexto de la pandemia de COVID-19. La micorriza emerge como una analogía de la relación que se construye entre maestro/a y aprendiz, vínculo socioemocional que se ha visto tensionado por la soledad y el aislamiento sanitario. Desde las lógicas que ofrecen las perspectivas del taller maestro/a-aprendiz, arte diseño, y expresión y creación personal (Raquimán y Zamorano, 2017), las artes visuales nos muestran un camino para mitigar los impactos del distanciamiento obligado, dado que permiten construir secuencias didácticas en donde los y las estudiantes pueden generar una sensibilidad exploratoria de los fenómenos de la naturaleza próxima como, por ejemplo, el jardín de la casa, y de los aspectos técnicos que se dan en diferentes medios de producción artístico visual como, por ejemplo, el montaje. En este sentido, las artes aportan con nuevas posibilidades de aprendizaje a los planos conceptual-racional y sensorial-emotivo dentro del sistema escolar chileno (Carvajal, 2013), lo que se amplificaría al vincularlas con otras asignaturas. En un escenario educativo de pantallas negras e insistencia en la aplicación de pruebas estandarizadas, lo anterior cobra una relevancia sustantiva y esperanzadora. 
La innovación educativa que es objeto de análisis en el presente artículo se ejecutó durante 2020 en el Colegio Cumbres del Choapa, establecimiento particular subvencionado de la ciudad de Salamanca (Región de Coquimbo, Chile). Su desarrollo se dio en el seno de un espacio de aprendizaje activo con escolares de enseñanza básica y media, denominado Cocinería, Arte \& Ciencia, el cual responde a la lógica de un laboratorio de ideas bajo un enfoque arte-cienciatecnología-sociedad, utilizando el método de proyectos en ciencias (Sanmartí y Márquez, 2017; Serón, 2019). El trabajo tuvo como objetivo construir montajes artísticos que dieran cuenta de la diversidad del reino fungi y evidenciaran analogías basadas en la relación simbiótica que es propia de la micorriza. La experiencia fue liderada por la profesora de artes del establecimiento, con el asesoramiento en biología de la Red de Observadores de Aves y Vida Silvestre de Chile (ROC) y la sistematización audiovisual de DollyBack Producciones Audiovisuales.

\section{Desarrollo de la innovación}

El año académico 2020 fue diseñado pensando en una participación presencial en los circuitos de congresos y ferias escolares como, por ejemplo, el Programa Explora. Sin embargo, en cosas de días, la pandemia de COVID-19 en Chile desmanteló todos los escenarios educativos perfilados, emergiendo la disyuntiva entre cancelar lo planificado o reorganizarlo. Se optó por lo segundo, esperando que la institucionalidad que sirve de soporte año a año para dinamizar proyectos escolares pudiera también reestructurarse, cuestión que afortunadamente se materializó. Es así como se adhirió al llamado de la Fundación Colorearte ${ }^{4}$ para implementar una instalación artística (land art), referida al reino de los hongos o reino fungi.

La invitación a trabajar con dicho reino resultó pertinente pues lo constituyen seres vivos muy desconocidos en Chile para la opinión pública, pese a lo cotidiana que puede llegar a ser su observación (Capetanópulos, 2018). Desde lo pedagógico, Oliveira y Santos (2017) han documentado cómo los hongos son un buen modelo para que los/as docentes investiguen y comprendan los saberes de los/as estudiantes y entiendan cómo estos pueden relacionarse con los contenidos que se enseñan en la escuela. En consideración a lo anterior, se tomó la decisión de explorar dos aspectos del vasto mundo de los hongos: la división de los Basidiomicetos,

\footnotetext{
${ }^{4}$ Véanse detalles de la convocatoria 2020 en: https://colorearte.cl/concursos/2020-reino-fungi/
} 
particularmente las especies con cuerpos fructíferos en forma de sombrero, los cuales son posibles de observar en otoño e invierno en macetas y jardines domiciliarios, y la asociación simbiótica planta vascular-hongo micorrizante.

Dos preguntas fundamentaron el diseño de la secuencia didáctica: ¿qué niveles de interrelación entre el concepto biológico de micorriza y su analogía social pueden ser comunicados mediante una instalación artística escolar? y ¿de qué manera podemos desarrollar la creatividad bajo un escenario de trabajo personal e íntimo y, además, tensionado por los impactos de la pandemia? Para responder a estas preguntas se delimitaron dos categorías de variables a ser trabajadas con los estudiantes: la categoría de lenguaje visual, que incorporó variables como espacio, morfologías (formas, patrones), punto, línea, plano, movimiento, dimensión, proporción, color, textura, expresión, y la categoría de lenguaje científico, que implicó el estudio de conceptos como reino biológico, reino vegetal, reino fungi, interacciones ecológicas, simbiosis, micorriza y red de la vida.

La secuencia didáctica se materializó como el proyecto Arte-Ciencia en Micorriza y se organizó en cinco etapas: 1) documentación; 2) lluvia de imágenes; 3) talleres; 4) manos a la obra; y 5) evaluación. Dichas etapas, como se muestra en la Tabla 1, dialogaron en términos generales con la propuesta metodológica que desarrolla la Fundación Colorearte para sus concursos anuales ${ }^{5}$.

\section{Tabla 1}

Secuencia didáctica ejecutada por el proyecto (izquierda) y etapas del método Colorearte

\section{Etapas de la presente innovación}

Documentación: construcción de un banco de datos fotográfico sobre hongos y estudio de los aspectos biológicos del reino fungi.

Lluvia de imágenes: confección y socialización de bocetos sobre hongos y la micorriza, y elaboración de bosquejos de montajes y preguntas sobre los hongos.

Talleres de autoaprendizaje: desarrollo de sesiones online de discusión guiada, con portafolio de organizadores gráficos para abordar el vínculo arte-ciencia-hongos.

\section{Etapas del método Colorearte}

Motívate: presentación del concurso y su tema anual a los/as estudiantes y convertir el mismo en un desafío pedagógico en equipo.

Investiga: estudio de la teoría del color y la instalación artística, experimentación de técnicas de teñido e integración del arte con las ciencias naturales para dar sustento al montaje.

Crea: definición de la propuesta de intervención y desarrollo de bocetos de montaje. Tinción de telas, producción de los diseños, montaje y registro fotográfico de la obra.

\footnotetext{
${ }^{5}$ Véase: https://colorearte.cl/wp-content/uploads/2020/04/ETAPAS-Concurso-Colorearte-2020.pdf
} 
Manos a la obra: trabajo en terreno, vía sala móvil, con talleres de tinción de telas para luego desarrollar los montajes en las locaciones seleccionadas por los/as estudiantes.

Evaluación: fotografías de los montajes y grabación de corto documental testimonial del proyecto, participación en ferias de ciencias y desarrollo de evaluación escrita.
Comunica: selección de material para enviar a evaluación del concurso, envío del mismo y divulgación del trabajo en la comunidad escolar.

Reflexiona: reflexión sobre los aprendizajes interpersonales cognitivos asociados a las asignaturas implicadas y los referidos a la gestión del proyecto.

\section{Resultados}

La etapa de documentación fue desarrollada por cada estudiante en los jardines de sus casas y los adyacentes, donde pudieron observar y dibujar los cuerpos fructíferos de diferentes especies de hongos de sombrero (periodo abril-mayo). Las sesiones de estudio del reino fungi y de discusión de los conceptos asociados a una instalación artística se organizaron en reuniones virtuales semanales, de una hora de duración. En la misma modalidad se llevó a cabo la etapa de lluvia de imágenes, donde cada estudiante fue presentando inquietudes sobre la temática (mayo-julio). A partir de esto, se consolidó un trabajo con 12 estudiantes de quinto básico a segundo medio.

En la etapa de talleres de autoaprendizaje (julio-agosto) se utilizó un portafolio impreso de trabajo para cada estudiante, el cual contenía 18 ejercicios prácticos en base a organizadores gráficos, bases de orientación y diarios de trabajo, entre otros instrumentos, que debían ser completados por los/as estudiantes con los apuntes obtenidos tras revisar charlas online y videos sobre el reino fungi, recursos que fueron seleccionados por el equipo docente (11 videos en total). En dicho portafolio, además, los/as estudiantes registraron sus testimonios frente al desarrollo de sus montajes. La etapa "manos a la obra" (septiembre-octubre) se ejecutó en el domicilio de cada estudiante, durante las fases sanitarias de transición y preparación. Para esto se adaptó la parte posterior de uno de los vehículos de los docentes, donde se dispuso de un set de materiales para la creación de los montajes, el cual fue rotando casa por casa. Con dichos insumos cada estudiante ejecutó su proceso de obra de manera individual en su hogar, como se muestra en la Figura 1, manteniéndose al tanto de los avances del resto de sus compañeros y compañeras durante las sesiones semanales de trabajo en línea. 
En consideración al desarrollo de la pandemia, se pudieron concretar al menos 5 visitas a los hogares de cada estudiante, donde se resolvieron dudas sobre el desarrollo de los procesos de tinción y montaje. Allí también se realizaron discusiones sobre la biología del reino fungi y la ecología de la micorriza, velando por su integración en las obras. En este sentido, la observación participante y las notas de campo permitieron caracterizar los aprendizajes logrados durante esta etapa (Tabla 2), constituyéndose los mismos en saberes fronterizos entre el arte y la biología.

\section{Figura 1}

Proceso de obra asociado a la construcción de montajes sobre el reino fungi
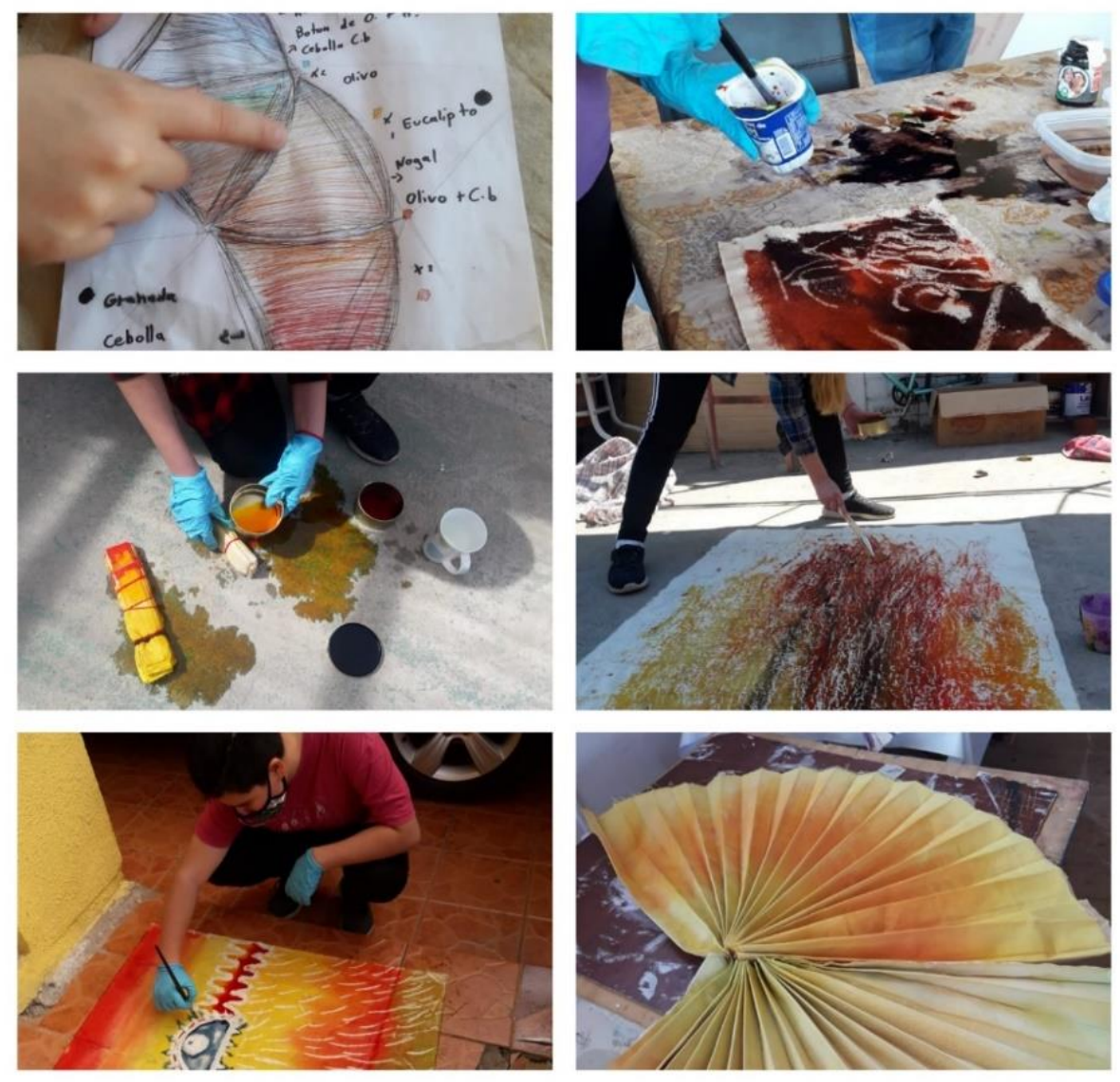

Nota: Fotografías de Cileni Pastén. 


\section{Tabla 2}

Caracterización de los aprendizajes en el campo de las artes visuales y la biología observados en la interacción con los/as estudiantes

Aprendizajes en Artes Visuales

\section{Aprendizajes en Biología}

- Incorporación de diferentes especies de hongos al acervo de experiencias vitales de cada estudiante, reflejado en el banco de imágenes que cada uno/a realizó de manera personal.

- Priorización de la idea biológica de trama de la vida, siendo el concepto de red de seres vivos el más destacado por los y las estudiantes.

- Incorporación del rol ecológico del reino fungi en el discurso estudiantil.

- Aprendizaje de nueva conceptualidad (por ejemplo, concepto de micorriza).

- Tratamiento de bordado como elemento plástico simbólico e iluminación escenográfica.

\section{Aprendizajes fronterizos}

- Trabajo de conceptos científicos en el mundo fungi para una relectura e interpretación mediante las formas artísticas.

- Observación consciente del fenómeno científico asociado a este mundo, intencionando una contemplación sensible para su interpretación estética.

Los logros en el desarrollo de habilidades y actitudes durante el desarrollo de la secuencia didáctica, especialmente en lo que respecta a la etapa de evaluación (octubre-diciembre), fueron los siguientes: 
a) Comunicación: pese a las restricciones sanitarias se logró mantener un contacto fluido con los y las estudiantes, mediante el uso de tecnologías masificadas en pandemia. En cuanto a las obras, estas establecieron relaciones visuales desde las ciencias hacia el elemento plástico.

b) Creatividad: el grupo en su conjunto fue capaz de proponer, de manera diversa, respuestas a su curiosidad sobre los hongos. Para ello, los/as estudiantes se valieron de la manipulación del espacio y la selección de un rincón en sus hogares, haciendo una adaptación equilibrada y armónica del tradicional land art.

c) Pensamiento crítico: se evidenció un despertar de la criticidad, revalorizando a un tipo de ser vivo olvidado y prácticamente ausente en el tratamiento de las asignaturas. Se realizó una lectura crítica del mundo escolar, relevando el taller como espacio educativo no escolarizante.

d) Colaboración: debido a la semipresencialidad, la colaboración se dio muy íntimamente entre maestro/a y aprendiz, pero sobre todo entre los/as estudiantes y sus familias. Pese a la ausencia de contacto físico, se observó un espíritu de grupo por medio de una conciencia de el/la otro/a y sus avances.

Finalmente fueron 8 los montajes terminados y 3 quedaron a la espera de ser finalizados tras el retorno a clases presenciales (Figura 2). Se participó de manera online en una feria de ciencia de Explora Coquimbo y en el encuentro organizado por la Fundación Colorearte, donde el trabajo fue reconocido como obra destacada. El corto documental con la experiencia se presentó en el IV Seminario Nacional de Didácticas Específicas en enero de 2021 (FID Usach, 2021). 


\section{Figura 2}

\section{Ocho obras sobre el reino fungi y la micorriza}
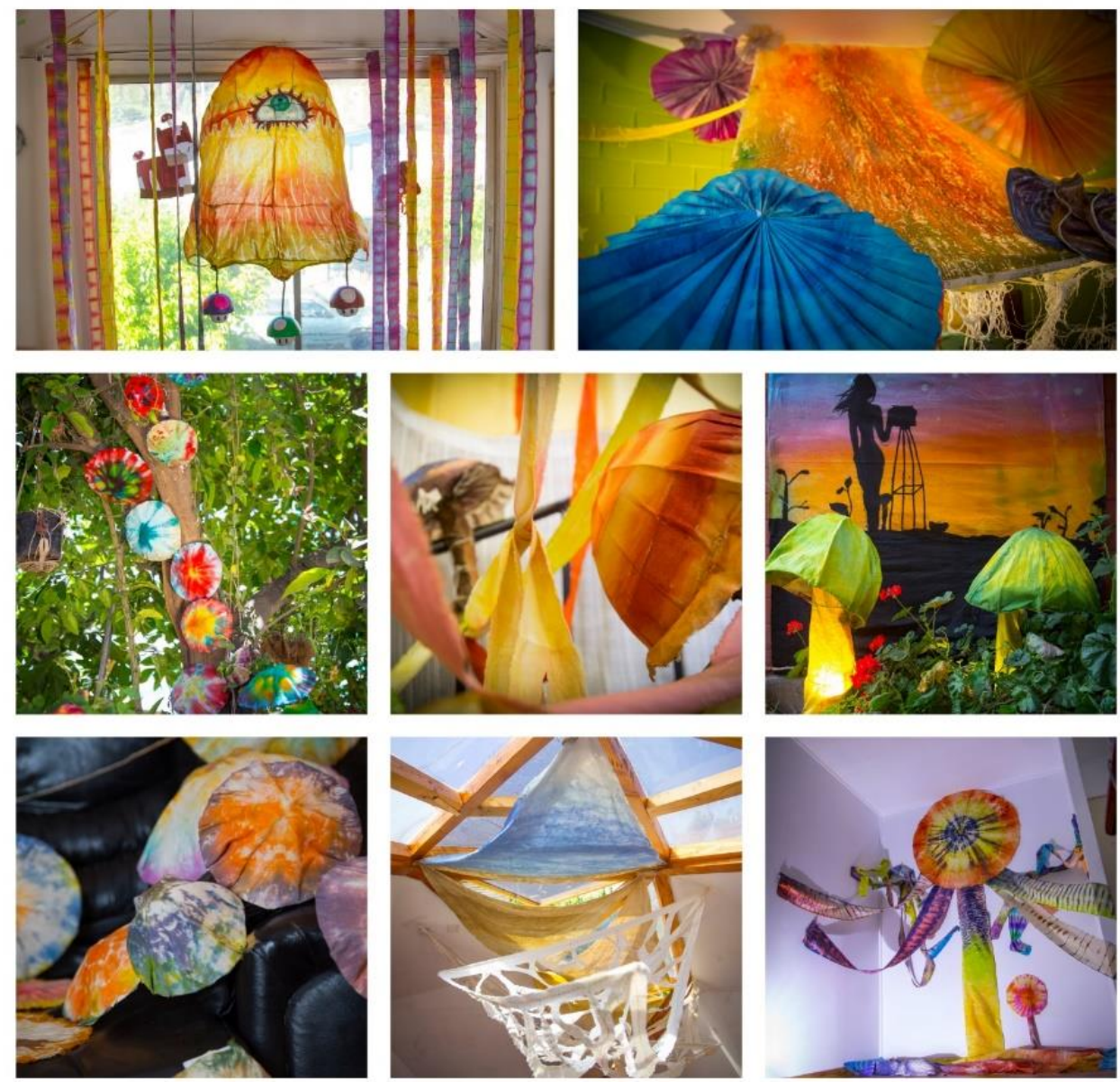

Nota. Fotografías de César Jopia.

\section{Discusión}

De acuerdo a Solís-Pinilla (2021), el desarrollo de proyectos con escolares impacta directamente en su desarrollo socioemocional, dimensión de lo humano que ha estado en tensión debido al aislamiento sanitario obligado. Si bien ha existido una preocupación por lo socioemocional, la escuela no necesariamente ha sabido responder a esta demanda desde la organización del currículum, manteniendo en líneas generales la atomización de las asignaturas, pese al nuevo escenario de posibilidades de experimentación pedagógica que ofrece la no presencialidad y las ventajas del método de proyectos para la integración curricular y el desarrollo de la creatividad, la 
autonomía y la motivación en el estudiantado (Serón, 2019; Sanmartí y Márquez, 2017). La priorización curricular de objetivos de aprendizaje y asignaturas generada por el Mineduc ${ }^{6}$, así como la insistencia de dicha cartera en la aplicación de las pruebas estandarizadas tipo Simce, podrían ser factores explicativos de las resistencias a la innovación didáctica en las escuelas.

En respuesta a estas tensiones, desde el mundo académico (Mesa de Trabajo Interuniversitario Educación COVID-19, 2020) y desde el profesorado (Colegio de Profesores TV, 2020) se ha visto en la nuclearización una propuesta didáctica pertinente para abordar los objetivos de aprendizaje del currículum de manera situada y en diálogo permanente con el contexto, sin una elección a priori de lo que es relevante o no. El proyecto Arte-Ciencia en Micorriza fue una materialización de dicha alternativa didáctica (véase Tabla 3) que consideró el aprendizaje por proyectos como un método que releva los intereses del estudiantado, incentiva la investigación creativa a partir de la búsqueda de información y pone en el centro la conversación entre los/as estudiantes y la valorización de su trabajo (Solís-Pinilla, 2021), cuestiones que en pandemia se vuelve una necesidad imperiosa recuperar.

Al respecto, Zamira, estudiante de primero medio, sostuvo que lo más importante de la experiencia fue "estar haciendo algo con otras personas, lo que me hizo recordar el estar en clases de artes en el colegio". Camila, compañera de curso de Zamira, reforzó el impacto del proyecto como experiencia de vida al señalar que "lo más importante para mí fue poder desarrollar algo y utilizar esa creatividad que se mantenía en un profundo sueño en esta cuarentena que parece eterna". Lo que plantearon estas estudiantes dialoga con lo advertido por Delannoy (2017) desde su propuesta de "neuroartes": es urgente el desarrollo de proyectos artísticos en el seno de comunidades educativas abiertas y flexibles que se pregunten por lo que es valioso (y lo que podría serlo en un futuro próximo) para la búsqueda del bienestar humano.

\footnotetext{
${ }^{6}$ Para conocer detalles sobre la priorización curricular dispuesta por el Ministerio de Educación chileno, véase: https://www.curriculumnacional.cl/portal/Secciones/Curriculum-transitorio/178042:Priorizacion-Curricular
} 


\section{Tabla 3}

Síntesis de objetivos de aprendizaje de las bases curriculares chilenas que fueron nuclearizados por el proyecto Arte-Ciencia en Micorriza

\section{Objetivos de aprendizaje - Artes Visuales Objetivos de aprendizaje - Biología}

- Crear trabajos de arte y diseños a partir de las propias ideas y la observación.

- Crear trabajos visuales a partir de la imaginación, experimentando con medios digitales de expresión contemporáneos.

- Crear trabajos visuales basados en la apreciación y el análisis de manifestaciones estéticas referidas a la relación entre personas, naturaleza y medioambiente.

- Crear obras y proyectos que respondan a necesidades de expresión y comunicación, personales o grupales.
- Reconocer y observar, por medio de la exploración, que los seres vivos crecen, responden a estímulos del medio, se reproducen y necesitan agua, alimento y aire para vivir, comparándolos con las cosas no vivas.

- Investigar y explicar cómo se organizan e interactúan los seres vivos en diversos ecosistemas.

\section{Objetivos de Aprendizaje - Orientación}

- Promover en el propio entorno relaciones interpersonales constructivas, sean estas presenciales o por medio de las redes sociales, sobre la base del análisis de situaciones.

Nota. Los objetivos descritos corresponden a las bases curriculares de $7^{\circ}$ básico a $2^{\circ}$ medio publicadas por el Ministerio de Educación en 2016.

Los programas de neuroartes señalados por Delannoy (2017) buscan vías hacia una cultura sostenible con personas autónomas, proponiendo una práctica que integre las artes con la educación filosófica y científica, y la participación equilibrada de educadores/as, niños, niñas, adolescentes, padres y madres. Matilda, en su sabiduría de adolescente, entregó luces acerca de cómo orientar dicho proceso en pandemia. Ella sostuvo que su momento favorito del proyecto fue "el pintar con telas, ya que mi familia me ayudó también y aprendimos algo juntos”. Camila, en la misma línea, develó los desafíos de un proceso de obra en la intimidad del hogar y cómo pudo resolver los ripios 
del proceso: "Tuvimos unas charlas sobre cómo sería el método que usaríamos para trabajar. Mi madre me dio ideas, las que descartamos entre ambas, dándome la mayor parte del trabajo a mí, como debe de ser, ya que este trabajo es de nosotros y ellos -los padres- están para darnos apoyo y no deben hacer el trabajo por nosotros".

Para el grupo de estudiantes participantes el periodo de confinamiento fue difícil de sobrellevar. Expresaron la añoranza de ver a sus amigos, amigas y educadores/as. La personalización del trabajo docente-estudiante se consolidó durante esta experiencia pedagógica como una forma de mitigar los efectos negativos de dicha realidad. Los y las estudiantes respondieron maravillosamente cuando fueron acompañados/as en sus procesos de obra en sus casas. Allí la micorriza no solo emergió como concepto de arte-ciencia, sino que también como metáfora de la relación maestro/aaprendiz, persona-persona, persona-familia (FID-Usach, 2021). Existió un tránsito desde la inseguridad derivada de la no presencialidad hacia una apuesta de obra en solitario y en co-diseño. Al respecto, Zamira señaló: "Uno de mis momentos favoritos fue cuando una persona que conozco me presentó un tronco pequeño para hacer texturas. Cuando lo fui a buscar con la profesora me emocionó mucho reconocer a alguien que veía en el colegio”.

No se puede obviar el hecho de que las exigencias académicas tradicionales de la escuela generaron una sobrecarga en los estudiantes, lo que tensionó su compromiso con el proyecto. Esto desafió la capacidad del equipo docente y obligó a abrir espacios de discusión crítica sobre las dinámicas enajenantes de la escolarización, mostrando a los/as estudiantes otras formas de aprender mediante la co-evaluación de sus producciones y subrayando contantemente la coherencia, la profundidad del proceso y la perseverancia para su desarrollo. Al respecto, Khiara sostuvo que la superación de las dificultades inherentes al proceso de obra pudo darse "haciéndolo una y otra vez hasta poder lograrlo, siendo perseverante".

Capetanópulos (2018) evidenció la desvalorización y escaso conocimiento que se tienen en Chile con respecto al reino fungi, identificando una serie de aspectos que limitan la comprensión de este vasto grupo de organismos, tales como su limitado estudio en la historia natural de Chile y su censura debido a creencias infundadas. En dicho escenario, la presente experiencia aporta con algunas directrices para articular iniciativas que superen el tratamiento descriptivo y utilitario del reino fungi que realizan algunas ramas de la biología y la economía. Los hongos no generaron un rechazo a priori en los estudiantes, más bien produjeron curiosidad. La mediación pedagógica 
durante el proyecto provocó no solo el desarrollo de la perseverancia en tiempos de adversidad, sino que también actitudes positivas hacia los hongos con los que convivimos. Al respecto, Diego sostuvo que el trabajo "fue entretenido, ya que me permitió conocer más del mundo de los hongos y el hacer muchos bocetos nos sirvió para plasmarlo en el montaje”. Khiara complementa y concluye que "además de aprender a teñir telas de diversas formas, reconocí la importancia de los hongos en el planeta y lo poco valorado que son".

Los procesos de obra finalizados establecieron una analogía entre la micorriza y las relaciones entre personas. Camila quiso conectar su proyecto y el de sus compañeros/as, posicionando su montaje en la ventana de su habitación, probablemente buscando unirse a través de otras ventanas con sus compañeros/as. Por su parte, Mariangel vio en la simbiosis de la micorriza denominadores comunes con el vínculo que se establece entre los miembros de una familia, plasmando en su montaje una micorriza y cuerpos fructíferos de colores evocadores del amor. En una línea de análisis personal, Matilda construyó analogías entre el sistema nervioso y el entramado de la micorriza, creando un nuevo ser mitad humano y mitad hongo, en una línea muy similar a la obra de Diego. Zamira, por su parte, evocó comparaciones entre la relación de crecimiento maestraaprendiz y la nutrición mutua que establece una planta vascular en relación con un hongo. Khiara, Emilia y la segunda Matilda del grupo, por su parte, evidenciaron en los múltiples colores y formas de sus obras fúngicas la diversidad de la vida y la curiosidad que la misma despierta en el ser humano. Estas analogías, en su componente visual y sonoro, a través del relato de sus propias protagonistas, pueden ser atendidas con mayor detalle en FID Usach (2021).

\section{Conclusiones}

La innovación implementada permitió la integración de disciplinas y asignaturas con un tema nuclearizante, poco abordado en el currículum. Esto facilitó que los y las estudiantes pudieran divertirse con sentido educativo, en pos del diseño y construcción de una obra propia (proceso de obra) que los/as interpeló en su creatividad y los/as llevó a crear de manera colectiva, es decir, en micorriza, a pesar de la pandemia. En este sentido, el periodo de aislamiento sanitario en 2020 fue una oportunidad para revalorar el fenómeno de la conexión como gatillador de analogías y montajes multicolores, en un ecosistema limitado de naturaleza antropizada como es el hogar, que, a fin de 
cuentas, fue la naturaleza más a mano durante la pandemia. En este sentido, si bien los resultados descritos en habilidades y actitudes se pueden lograr con otras temáticas de la vida silvestre, la micorriza ofreció horizontes de exploración artística que desafiaron y resignificaron la soledad propia del confinamiento derivado de la pandemia, dando una impronta situada a la experiencia de aprendizaje.

El trabajo en base al método de proyectos con un enfoque de arte-ciencia resultó del todo pertinente a las inquietudes estudiantiles relacionadas con la pertenencia a un grupo. En ese sentido, estrategias como la apreciación artística, el aprendizaje de técnicas y el uso de la naturaleza próxima, colaboraron al propósito de desarrollar un espíritu sensible y crítico que pueda dar acceso a los y las estudiantes a la tan ansiada autonomía, una facultad que emerge como fundamental en el actual escenario de crisis sanitaria y social que vive el mundo. Creemos que la nuclearización de objetivos de aprendizaje y habilidades socioemocionales es el camino, en lo pedagógico y afectivo, que deberemos co-construir entre pares docentes, aprendices y familias.

\section{Referencias}

Carvajal, M. (2013). El papel del arte en la educación. Una mirada crítica desde el contexto actual. Revista de Pedagogía en Música, 1(1), 37-51.

Capetanópulos, A. (2018). Un desconocido reino a tus pies: el escenario de los hongos en Chile. [Memoria de Título no publicada]. Universidad de Chile. http://repositorio.uchile.cl/handle/2250/168447

Colegio de Profesores TV. (02 de junio de 2020). Nuclearización: la propuesta del magisterio para abordar el currículum durante la pandemia. [Archivo de Video]. Youtube. https://youtu.be/aTdL8xczBUI

Delannoy, L. (2017). Neuroartes, un laboratorio de ideas. Ediciones Metales Pesados.

FID Usach. (14 de enero de 2021). Cápsula: Arte-Ciencia en Micorriza. [Archivo de Video]. Youtube. https://youtu.be/JQyXXVaC-1A 
Mesa de Trabajo Interuniversitario Educación COVID-19. (2020). Didácticas para la proximidad: Aprendiendo en tiempos de crisis. Santiago de Chile. http://educacion.uc.cl/images/documentos/informe-didactica-final.pdf

Ministerio de Educación (2016). Bases Curriculares $7^{\circ}$ Básico a $2^{\circ}$ Medio. Unidad de Currículum y Evaluación. Ministerio de Educación de la República de Chile.

Oliveira, E. y Santos, G. (2017). Un recurso acerca de los hongos para el diálogo intercultural en la enseñanza de biología. Góndola, Enseñanza y Aprendizaje de las Ciencias, 12(2), 142157.

Sanmartí, N. y Márquez, C. (2017). Aprendizaje de las ciencias basado en proyectos: del contexto a la acción. Ápice. Revista de Educación Científica, 1(1), 3-16.

Serón, F. (2019). Arte, ciencia, tecnología y sociedad. Un enfoque para la enseñanza y el aprendizaje de las ciencias en un contexto artístico. Revista Iberoamericana de Ciencia, Tecnología y Sociedad, 14(40), 197-224.

Solís-Pinilla, J. (2021). Aprendizaje basado en proyectos: una propuesta didáctica para el desarrollo socioemocional. Revista Saberes Educativos, (6), 76-94.

Raquimán, P. y Zamorano, M. (2017). Didáctica de las Artes Visuales, una aproximación desde sus enfoques de enseñanza. Estudios pedagógicos, 43(1), 439-456. 